\title{
Article
}

\section{An Attachment aware schools programme: a safe space, a nurturing learning community}

Kelly, Paul, Watt, Lizzie and Giddens, Sara

Available at http://clok.uclan.ac.uk/33289/

Kelly, Paul, Watt, Lizzie and Giddens, Sara ORCID: 0000-0003-0680-2189 (2020) An Attachment aware schools programme: a safe space, a nurturing learning community. Pastoral Care In Education, 38 (4). pp. 335-354. ISSN 0264-3944

It is advisable to refer to the publisher's version if you intend to cite from the work. http://dx.doi.org/10.1080/02643944.2020.1751685

For more information about UCLan's research in this area go to http://www.uclan.ac.uk/researchgroups/ and search for < name of research Group>.

For information about Research generally at UCLan please go to http://www.uclan.ac.uk/research/

All outputs in CLoK are protected by Intellectual Property Rights law, including Copyright law. Copyright, IPR and Moral Rights for the works on this site are retained by the individual authors and/or other copyright owners. Terms and conditions for use of this material are defined in the policies page.

\section{CLoK}

Central Lancashire online Knowledge www.clok.uclan.ac.uk

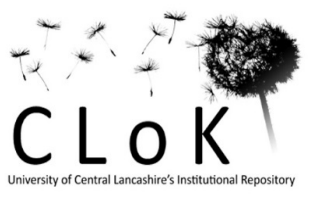




\section{Title Page:}

\section{An Attachment Aware Schools Programme: A Safe Space, a Nurturing Learning}

\section{Community}

\section{Author details:}

Dr Paul Kelly, Lizzie Watt and Dr Sara Giddens

info@paulkellypsychology.co.uk, lizzie.watt@derbyshire.gov.uk, sgiddens@uclan.ac.uk Contact: Dr Paul Kelly, Specialist Senior Educational Psychologist, Virtual School, or Lizzie Watt, Assistant Headteacher, Virtual School

Chatsworth Hall Block B, Chesterfield Rd, Matlock, Derbyshire DE4 3FW. 01629538028

\section{Dr Sara Giddens}

Dr Sara Giddens is a choreographer and lecturer (University of Central Lancashire), with a background in Performance, Creative Social Pedagogy and Action-Research. Throughout the programme Sara has been providing theoretical and practical ways to approach and employ action-research within each of the settings.

\section{Dr Paul Kelly}

Dr Paul Kelly is the Specialist Senior Educational Psychologist with the Virtual School for Children in Care in Derbyshire County Council. Paul's doctoral research highlighted the importance of collaborative working with schools and settings in understanding and applying attachment theory, and its implications, for all children, young people and adults. He has jointly pioneered the Attachment Aware Schools programme in Derbyshire. 
Lizzie Watt

Lizzie Watt is the Assistant Headteacher, leading on innovation, Teaching and Learning for Derbyshire's Virtual School. Lizzie has completed a Master's in Education, which focused on the increasing responsibilities for schools to support emotional health and wellbeing. Lizzie is co-founder of the Attachment Aware Schools programme: A Safe Space, A Nurturing Learning Environment.

\title{
An Attachment Aware Schools Programme: A Safe Space, a Nurturing Learning
}

\section{Community}

\begin{abstract}
There is a growing expectation that schools have a good understanding of attachment theory and its implications in practice (NICE, 2015), in order to meet the needs of Looked After Children, and other vulnerable learners. Derbyshire County Council's Attachment Aware Schools programme, now in its fifth year, is meeting this need by providing a substantial school development programme which has led to innovative and sustainable ways of developing school practice.
\end{abstract}

This programme has involved a comprehensive range of bespoke long-term development work with 77 schools to date, through a dynamic interaction of training, action research and reflective practice to promote safe, nurturing and effective learning environments. The programme, underpinned by attachment theory (Bowlby, 1969), has led to schools throughout the county becoming communities of inquiry and hubs of excellence, through a process of practice-as-research, where the cyclical nature of action research enhances the 
complementary relationship of theory and practice.

Evaluation of the programme has shown that all participating schools have effected ethos change, and developed better informed pedagogical practice, to support Looked After Children, and other vulnerable learners. This article explores how building attachment awareness in schools, with a focus on relationship-building and a better understanding of teacher-pupil interaction, can contribute meaningfully to whole school development.

\section{Key Words}

Attachment Awareness, Action Research, Reflective Practice, Looked After Children, School Development, Pedagogy, Care, Behaviour

\section{Introduction}

The 2015 NICE guidelines oblige schools to be appropriately trained to meet the requirements of children with attachment needs (NICE, 2015). Schools want, and need, support on how to work more effectively with children and young people with behaviour which challenges others; often arising from unmet attachment needs.

The Children and Families Act (2014) directed Local Authorities in England to establish a 'Virtual School Headteacher' who would monitor and support the education of Looked After Children in that authority. Many Local Authorities then chose to develop teams to carry out these duties under the direction of their Virtual School Headteacher. The term 'Virtual School' refers to such a team and they hold a 'virtual' school roll to monitor all the Looked After Children within their authority as though they were together in the same physical school. This includes monitoring and supporting their attendance, attainment, progress and 
other factors. The Attachment Aware Schools programme (AAS) in Derbyshire was designed by the Virtual School to support a network of schools and settings to develop innovative and excellent pedagogy around supporting vulnerable learners, and to improve the teaching and learning conditions for Looked After Children (in Derbyshire referred to as Children in Care) and all vulnerable learners. Throughout the programme, the aim is to capitalise upon the good working relations between the Virtual School and Derbyshire schools, and to support and disseminate good practice through encouraging innovative school development.

The AAS programme is now entering its fifth year with 77 schools having (or currently) taken part (representing over 34,000 children and young people) and over 500 delegates attending the five AAS conferences and sharing events. The evaluation and evidence that is drawn upon in this writing is focused on the data collected from the Year 1 cohort of 17 schools (2014 - 2015).

There is a growing use of the term 'attachment awareness' in schools, both nationally and internationally, and this approach to practice in schools is growing in scope and scale. 'Attachment awareness' is a term which is used to describe an approach which is founded on understanding attachment theory and using this knowledge to shape pedagogy and practice. Attachment theory itself underpins this work, and the key proponent of attachment, John Bowlby, described the process of attachment by saying, '[an infant] is strongly disposed to seek proximity to and contact with a specific figure and to do so in certain situations, notably when he[/she] is frightened, tired or ill' (Bowlby, 1969, p.371). This proximity-seeking is, in a securely-attached relationship, responded to by the caregiver attempting to meet the infant's needs. For this to happen, the caregiver must be 'attuned' to the infant's physiological and emotional needs, and must demonstrate their attunement through their response (Trevarthen, 
2011). Through this process, the caregiver becomes a 'secure base' for the child and provides nurture and security for the child to return to for support in times of distress (Bowlby, 1988). Children may seek their caregiver by displaying behaviours which cause the caregiver stress which forces an imperative for action and response. These kinds of behaviours range from an infant crying to a teenager demonstrating poor behaviour in school; in both cases acting as an 'attachment' behaviour to seek the support of the caregiver (or other adult in loco parentis). Differing parent-child interactions in this attachment process produce different attachment patterns (Ainsworth, 1969).

Building attachment awareness in schools endeavors to equip adults with greater knowledge, understanding and practice which is better attuned to all children and young people, and is informed by attachment theory. This includes developing a deeper understanding and knowledge of the neuropsychology of child development, and in particular, the processes of the flight/flight/freeze response, toxic stress and trauma which is imperative for Looked After Children who have experienced loss and trauma (Cairns, 2004). Due to changes in brain structure of Looked After Children who have experienced trauma and those with attachment disorder, they have a propensity to difficulties with emotional regulation (Schore, 2001; Schore, 2002) which can impact on behaviour and performance in school (Sebba, 2018). Regardless of the attachment pattern which a child develops, adults in school have the potential to enhance their teacher-child relationships which is a contributing factor to school success and happiness (Geddes, 2006). These improved and strengthened relationships contribute to a child's sense of belonging in a school which is a protective factor in terms of school satisfaction and attendance (Bergin and Bergin, 2009). In the words of Cozolino: 'Those who are nurtured best, survive best. It turns out that emotional resilience and our ability to learn are inextricably linked' (Cozolino, 2014). 
Shaped by previous research conducted in Derbyshire (Kelly, 2011), previous school development work and the NICE guidelines on attachment, Derbyshire's AAS programme began from a belief that there is a need to consistently challenge and develop thinking and understanding of the behaviours of children, young people and adults, and moreover, a greater understanding of attachment theories provides a very useful and pragmatic lens through which to see and reflect upon such behaviours. The NICE guidelines on attachment (NICE, 2015, 1.2.2) outline the importance of 'schools and other education providers' in ensuring 'that all staff who may come into contact with children and young people with attachment difficulties receive appropriate training on attachment difficulties.'

Virtual Schools have the responsibility to oversee the education of Looked After Children (Children in Care) and it is widely accepted (Bazalgette et al, 2015) that these young people benefit from a nurturing, attuned approach, which is grounded in attachment theory. There is a growing evidence base in international research of the effectiveness of whole school attachment-based strategies being effective for Looked After Children, and all children, in decreasing sanctions, exclusions and overall difficulties whilst improving pupil and adult outcomes (Rose et al, 2019; Parker et al., 2016). However, an attachment aware approach is not only beneficial for Children in Care; attachment is a universal process, which is fundamental to the healthy development of all young people and adults. Therefore, a good theoretical understanding of this, coupled with the ability to develop related practical approaches, will furnish schools with the necessary skills to show best practice in becoming attachment aware schools. 
Kelly’s research (2011), using a paradigm of Personal Construct Psychology (Kelly, 1963), identified the 'constructs' of attachment in school. Through semi-structured interviews with teachers $(n=5)$ and Educational Psychologists $(n=5)$, and repertory grids with each (Kelly, 1963), the research identified which elements of attachment theory were already well understood in schools and how practice was shaped by these. It also identified where schools could benefit from input in other aspects of attachment theory. The evidence showed three important points, amongst a range of recommendations for working effectively with schools around the area of attachment theory and practice:

- To support teachers who do not show practitioner intuition about attachment.

- To help teachers link their practitioner intuitive understanding of attachment with attachment theory.

- To highlight the importance of the cognitive perspective of attachment theory with teachers in particular.

Firstly, there was already a high level of practitioner intuition in some staff around attachment awareness, yet there was a gap in mapping the existing attachment theory (Bowlby, 1969) onto this practice and understanding the role of adults in school as secondary attachment figures (Bowlby, 2007). Secondly, the research confirmed the need to up-skill all staff in schools using the most recent research evidence in neuroscience and attachment (Schore, 2001) in order for them to better understand the needs of all children and young people. This included children with unmet attachment needs, but also positioned the attachment process as central to the relationships of all staff and all children and young people. The research also demonstrated a need for continued training, input and support for teachers and other colleagues in schools in Derbyshire which was grounded in attachment theory; this was instrumental in the design of the bespoke Derbyshire AAS programme. 
'Attachment Aware Schools' may well be a term used by a number of different local authorities (Parker et al., 2016), but it is important to recognise that it is not a licensed training product or prescribed programme that is delivered in the same way by all those using this term. Derbyshire's AAS programme invites schools to apply for and, if successful, commit two members of staff (including one from their Senior Leadership Team (SLT)) to a yearlong programme and ongoing network. The initial application asks schools to vision a project that would tackle an issue of school improvement they wish to work upon and would be significant to their setting. The Derbyshire AAS programme has three strands (see Figure 1). The taught programme focusses upon: the implications of attachment theory, behaviour and the physical environment, understanding trauma, and emotion coaching, accompanied by (downloadable) e-learning materials for each school. Through these taught elements, participants learn about the neuroscience and neuropsychology of attachment and trauma, and the sensory world of children and young people and how they respond to their environment. The emotion coaching training equips staff with the skills to implement this approach in their school and to cascade this to others. Group discussion and reflective practice in the taught sessions provide opportunities for embedding understanding and exploring how to bring theory into practice. The action research project, bespoke to each school, is supported by a research associate and a bursary to support the resourcing of their related work. Through regular attended sessions $(n=6)$ and action research visits in the school $(n=3)$, the programme leads were able to encourage the schools to design their own action research in their individual school, whilst also contributing to help shape the research question and ensure that the action research was a 'good fit' within the paradigms of the programme. Training was given regarding action research methods and support and guidance was in place throughout, meaning that any difficulties the participants encountered in the process were adequately 
supported by the programme leads and also the community of inquiry of the other participating schools. Action research is employed as a driver for school improvement and change, with a requirement that each setting must participate in ongoing evaluation and share their findings with the wider Derbyshire AAS network, in order to facilitate the sharing and discussion of best practice across the county. 
Figure1 


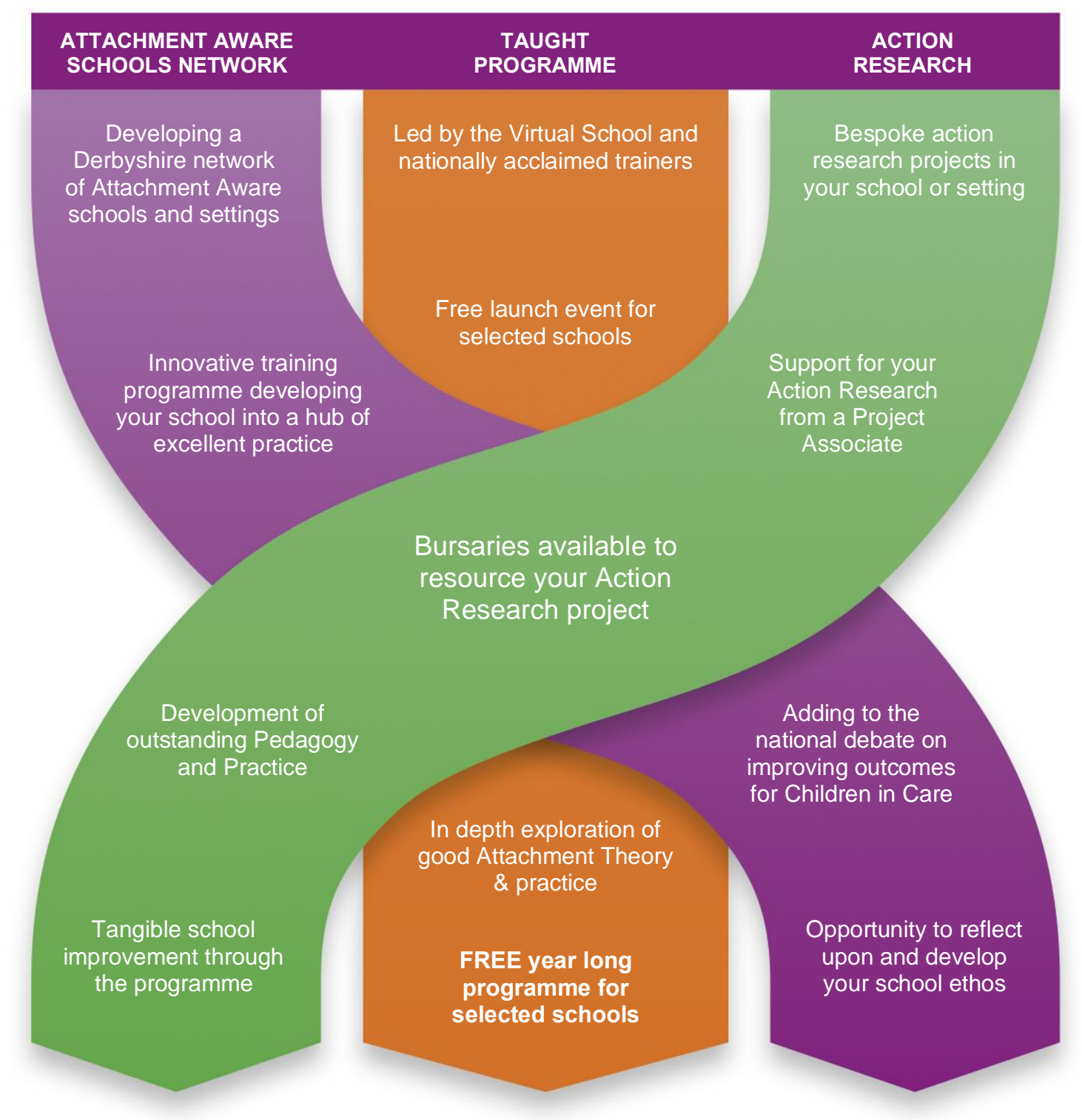




\section{Materials and methods}

One part of the range of evaluation undertaken across the Year 1 AAS cohort has been to measure the 'attachment awareness' of staff in each school through pre and post questionnaires and also through a face-to-face audit interview six months after completion of the programme, thus forming a mixed-methods evaluation (Stevenson \& Copper, 1997). The interviews were semi-structured and were held jointly with one of the AAS programme leads and the two participants from the school. 17 schools took part including:

- 5 Secondary schools (average no. pupils $=1015$; range $668-1309$ )

- 2 Special schools (mixed phase) (average no. pupils $=77$; range $72-82$ )

- 1 Pupil Referral Unit (mixed phase) (number of pupils <10).

- 2 Junior schools (average no. pupils $=208$; range $183-233$ )

- 5 Primary schools (average no. pupils $=143$; range $93-207$ )

- 2 Infant schools (average no. pupils $=131 ;$ range $81-180$ )

These schools were from rural and semi-rural locations, due to the geography of the local authority they were in, and the numbers of Children in Care in the schools ranged from $0-6$. The questionnaires were designed to elicit the progress made by schools on their journey to becoming more Attachment Aware. The evaluation participants were selected by the individual schools and included headteachers, teaching staff, teaching assistants, and a range of support staff; in other words, the full range of staff in schools who have contact with the children and young people.

The questionnaires asked participants to rate responses on a scale of 0-10 (with 10 being the most positive response) to the following four questions to produce quantitative data (Willig, 2001): 
(1) How attachment aware would you rate yourself as an individual?

(2) How would you rate your current knowledge and understanding of attachment theory?

(3) How much training/ learning have you undertaken in understanding attachment?

(4) Overall, how attachment aware is your whole school community?

At the end of the Year 1 Programme, each school was invited to answer two qualitative questions:

(1) At this point, how has the attachment awareness programme influenced attitudes, systems and/or policy in your school community?

(2) Who has this impacted on?

In addition, all of the 17 Year one participating schools were then audited, in a face to face interview, six months after the programme ended, to produce further qualitative data through thematic analysis (Braun \& Clarke, 2006).

From the outset, this evaluation gained ethical approval from the Virtual School Headteacher and informed consent from all the headteachers of the participating schools. The names of participants in the evaluation were not used, in order to protect anonymity as recommended by the British Psychological Society Code of Ethics and Conduct (2006; 2018). Participants gave voluntary informed consent to take part and were free to withdraw their information from the evaluation at any stage without question or reproach.

\section{Results}

Overall, 263 'pre' questionnaires were received with the following break-down by role:

- Headteacher $(\mathrm{n}=6)$

- $\quad$ Teacher $(\mathrm{n}=137)$ 
- Teaching assistant $(\mathrm{n}=78)$

- Other roles $(n=42)$

Subsequently, 154 'post' questionnaires were received as follows:

- Headteacher $(\mathrm{n}=6)$

- Teacher $(\mathrm{n}=71)$

- Teaching assistant $(\mathrm{n}=50)$

- Other roles $(\mathrm{n}=27)$

Analysis of the Whole School Questionnaires quantitative date yielded the following mean average point score increases reported overall by the Year 1 cohort of schools:

- $75 \%$ increase in average point score of attachment awareness as individuals.

- $100 \%$ increase in average point score of knowledge and understanding of attachment theory.

- $100 \%$ increase in average point score of training/ learning undertaken in understanding attachment.

- $133 \%$ increase in average point score of attachment awareness of their whole school community. 


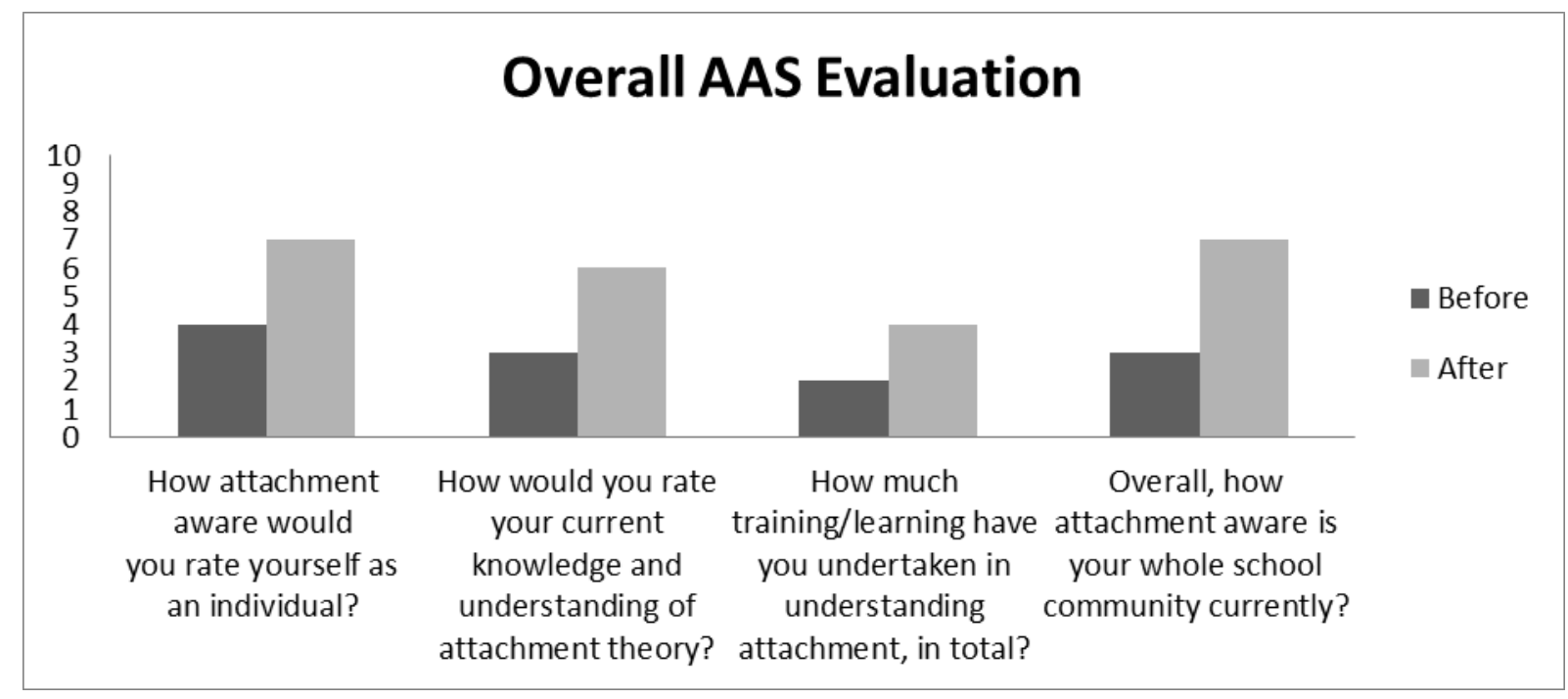

The largest overall point score difference from pre to post (and therefore suggesting the largest impact) was seen in the overall attachment awareness of the whole school community.

This is an important factor as this is a necessary aspect of sustainable whole school change.

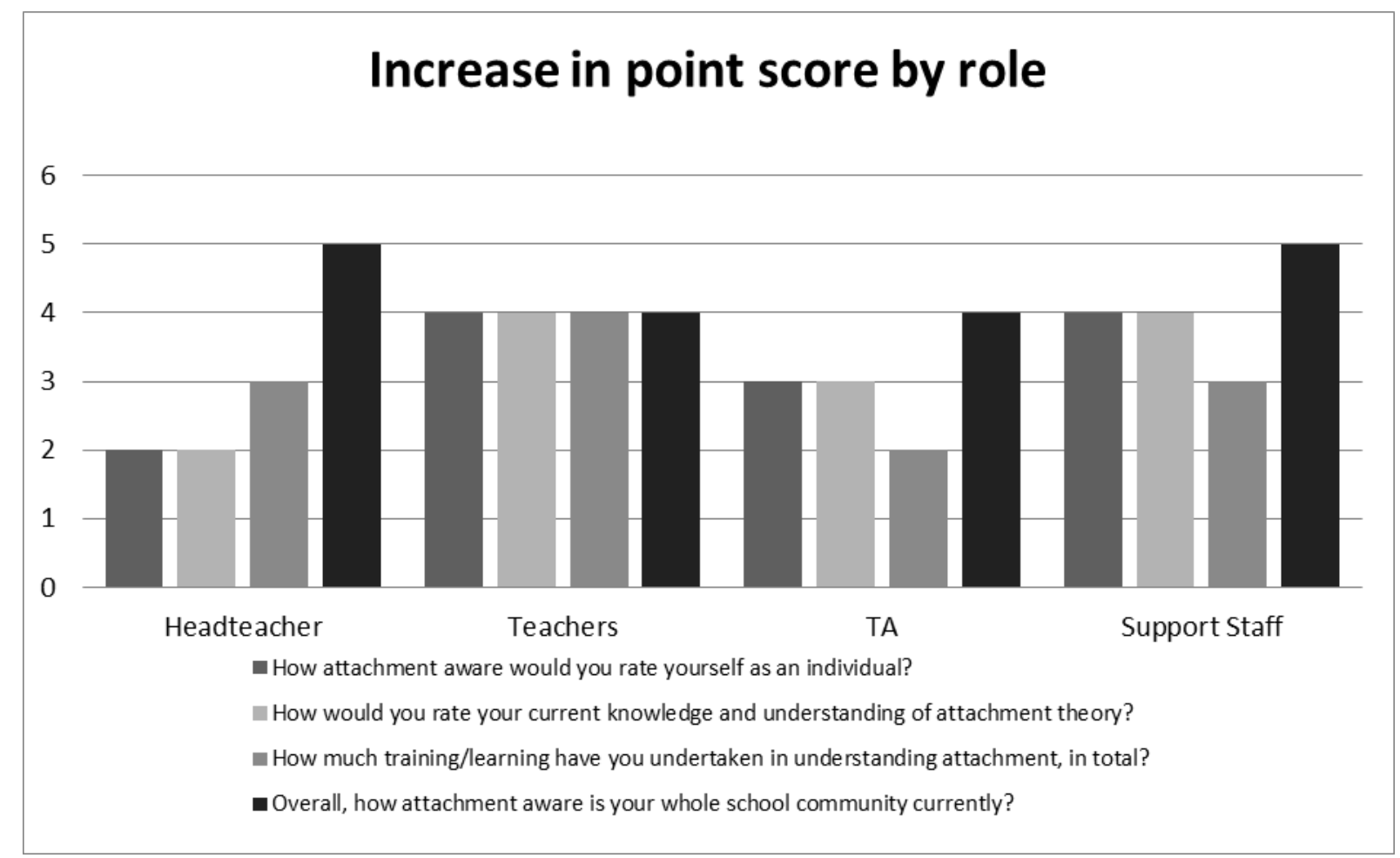

Headteachers reported improvements in all areas surveyed, with the greatest progress made in terms of the attachment awareness of the whole school community: 


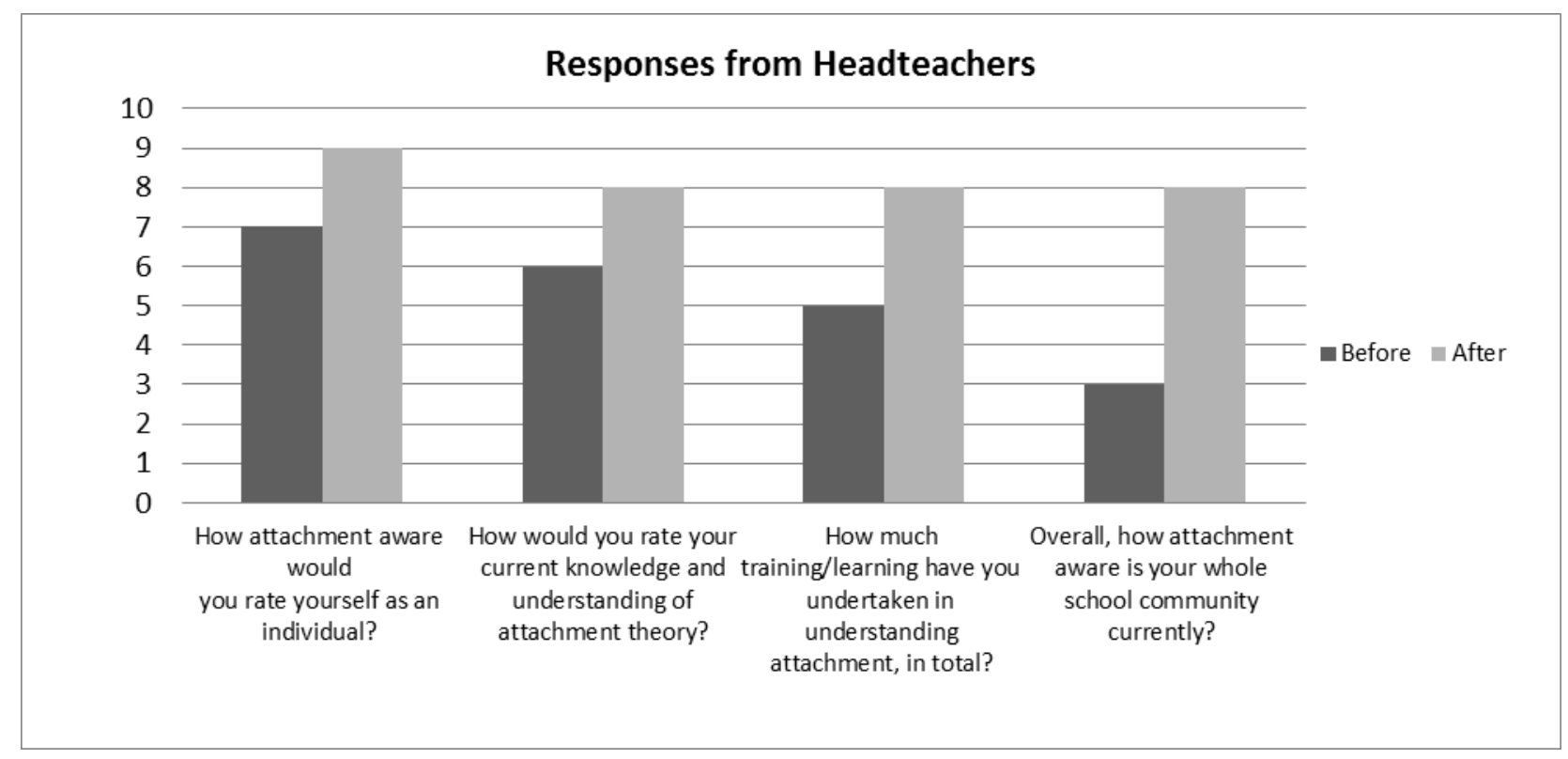

Teachers reported equal improvements in all areas surveyed:

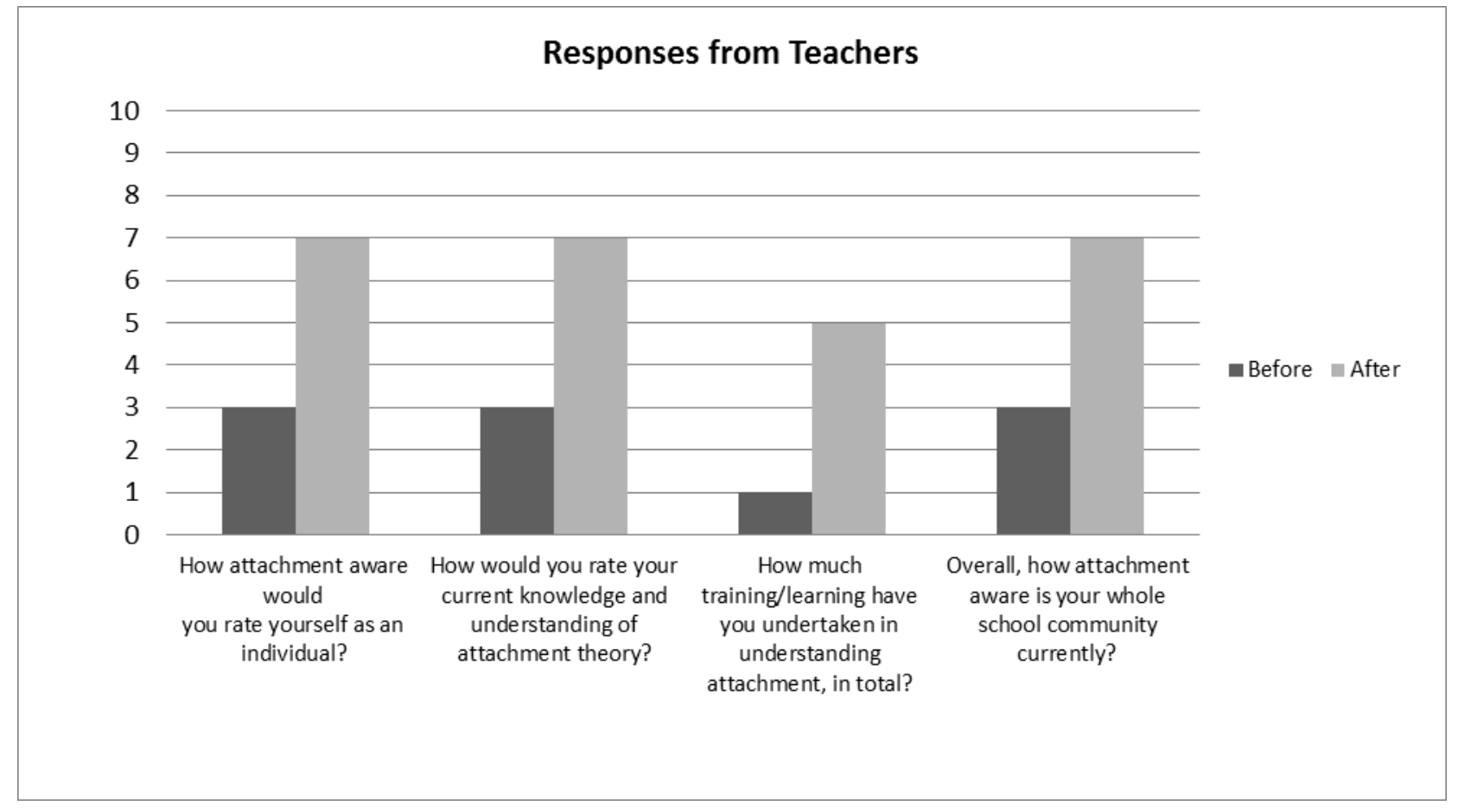

Teaching assistants reported improvements in all areas surveyed, with the greatest progress made in terms of the attachment awareness of the whole school community: 


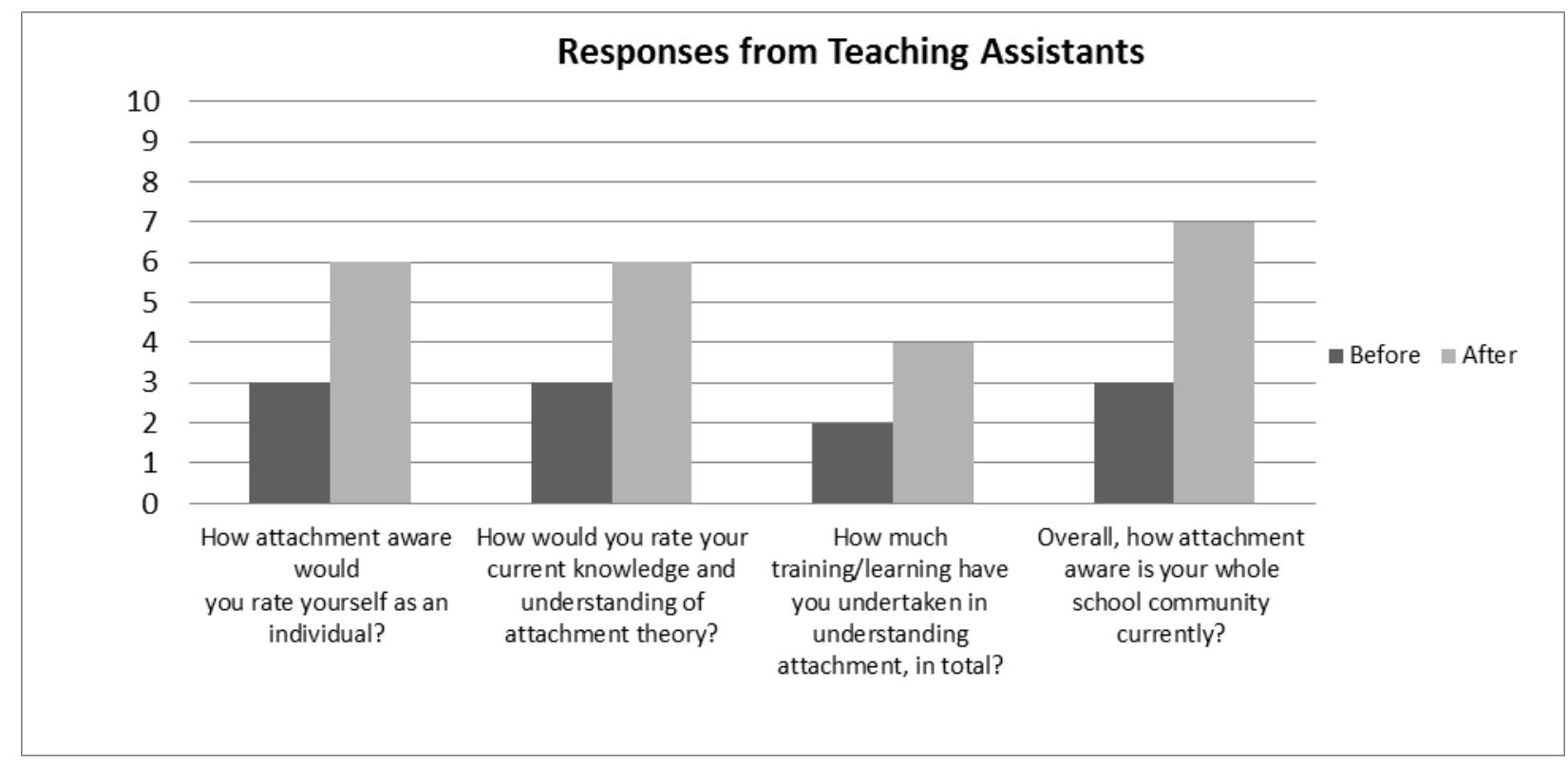

Support staff reported improvements in all areas surveyed, with the greatest progress made in terms of the attachment awareness of the whole school community:

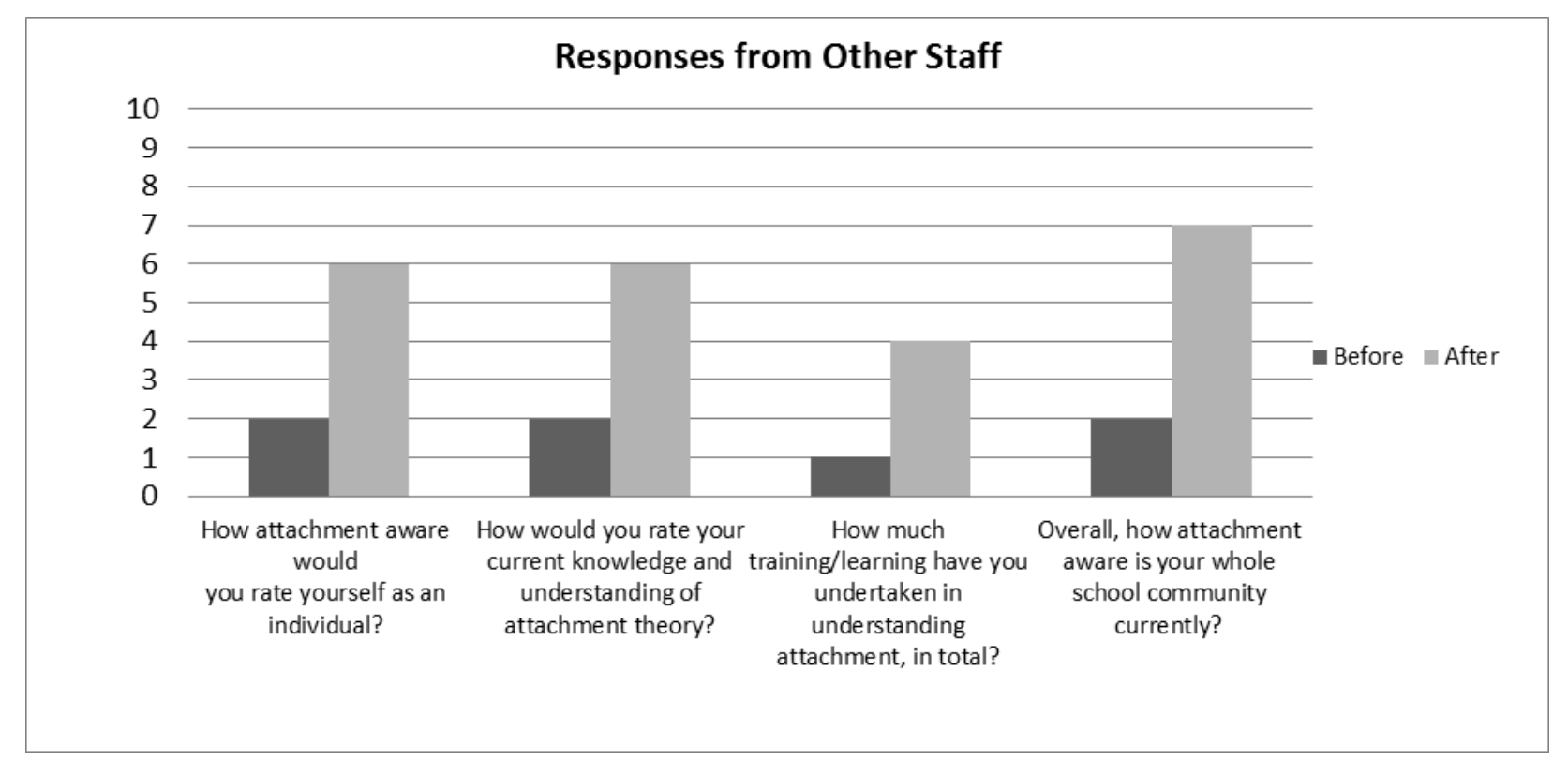




\section{Discussion}

We were fundamentally interested in what had transformed in school, how this change had come about and, perhaps most importantly, why these transformations had made a difference. The categories, themes and practice outlined below were all referred to by the schools in their questionnaires, interviews and audits. The greatest impacts identified by the schools were clustered around the following five areas, which are expanded upon below:

\section{- Developing Policy and Systems}

- Transforming Environment

- Staff and Pedagogical Development

- Impact on Pupils

- Extending relationships with parents/carers

\section{(1) Developing Policy and Systems}

Changes and challenges to ethos through a growing understanding of attachment needs has inevitably led to the necessity to 're-evaluate' and develop policies and systems in many of the AAS schools. One school reported how their pastoral policies now stem from a whole school awareness of the impact of attachment on children and families, and another on how their SEND policy now refers specifically to attachment issues and needs. Others reflected upon changes they have made to progression, and how in light of the AAS programme, their transition plans have been significantly improved. Another suggests that in response to their learning from the programme they have made changes to their exclusion policy in order to be more flexible and more sensitive to a wider range of children and young people's needs and backgrounds. For one school this has included the introduction of a vertical tutoring system for all Year 7-11s in order to create a more 'family-focused' ethos in school. Being more sensitive to, and aware of, such issues has led to schools making significant changes to their 
safeguarding procedures. Such reflections upon procedures have resulted in improved monitoring, recording and action; 'a lot of the initiatives currently in school are directly linked to attachment awareness'.

\section{(2) Transforming Environment}

For many of the schools and settings, developing a safer and more nurturing environment has meant making physical changes within and outside of their conventional classroom spaces. The busyness of schools was often remarked upon, as schools became more aware of the need for a safe, quiet space within their busy school, to allow children time to talk and share, or to be calm. Some schools have named specific places outside of the classrooms where young people can go to calm down. In some schools, specific areas have been established within classrooms, very often based on feedback from pupils regarding colours, lighting, furnishings and other environmental factors. Making such changes has always required investing in creating, and employing, different methods of listening to students and staff about their current concerns in order to identify the 'less safe' places around school; for example, areas where students could turn off lights making it dark especially around stair wells. This person-centred approach has led to practical and pragmatic solutions, sometimes demanding further resourcing, but very often re-using materials and resources the schools already had in a different place or a different time, and adjusting existing timetables to ensure that all staff and young people could access a new resource or opportunity.

In many of the schools, particularly the primary schools, making changes to the physical environment has spread across the whole school, leading to many classrooms now having a safe space through a process of experimentation, which has led to profound insights into how individual pupils can respond very differently to their classroom environments. This was reflected by a participant from an infant school who noted 'we have an insight into how pupils can respond very differently to our classroom environment.' 


\section{(3) Staff and Pedagogical Development}

Of course, it is the human interaction within any space that is fundamental to the way that a space functions. Trusted adults and their everyday practices can very often be the students' safe place. Children and young people do not differentiate who they feel safe with by role or hierarchy, but rather by the quality of the inter-personal relationship. The AAS Programme helped the schools to focus on the identification of key adults for vulnerable learners, at all levels within the schools staffing structure. In some settings, the Designated Teacher role has been expanded and re-modelled, and in many more schools the necessity to identify and name a safe adult for each child with emotional difficulties, has become paramount. This has included an emphasis on the child themselves identifying who they would like this to be. Reflecting upon this role, with adults and young people, has revealed that this key adult often provides both a familiar face and a familiar routine, is a good listener who makes the young person feel more valued, and is available in difficult points of transition such as breaks and lunchtimes. Knowing who this person is, and where they can be found, enables de-escalation of situations sometimes avoiding conflicts or unwanted behaviours. Ultimately, through modelling behaviour as simple as 'sharing and talking' adults can help to co-regulate emotions with young people. Such strategies have required some schools to re-think their approach to human resourcing in the school, approaching resourcing from a different, more inclusive and person-centred perspective. One headteacher commented: 'a budget has been allocated for additional staffing to allow one to one wellbeing sessions to be delivered across the week by the right staff member' and for many schools this has highlighted the importance of a flexible and responsive approach.

In many cases, small changes have reaped significant rewards. Several schools have changed the structure and timetabling of their working pattern, creating a rota, with a reliable routine 
that ensures a member of staff welcomes each child into school at the start of the day, so that each child feels valued and noticed. Such a welcome also gives young people an opportunity to talk over worries before lessons begin, providing the likelihood of a more positive start to their day. This helps to create a sense of belonging and strengthens relationships, through forming an attachment which makes them feel important and valued and helps to make the school feel safe. In turn, this increases the likelihood that any issues can be resolved 'there and then' before timetabled lessons begin.

Moreover, the programme has consistently supported the development of pedagogical practice, encompassing head-teachers, teachers, TAs, and other adults in school. The aim was to have some impact on the practice of all the staff in each AAS school; this was certainly easier in smaller primary schools, than larger secondary schools, but nevertheless has been seen across all phases and types of school. To effect this change, the two staff from each school who attended all the compulsory training days and led the action-research back in their settings, became attachment aware 'ambassadors' or 'agitators', modelling and sharing their developing knowledge and good practice both within everyday practice and through bespoke in-house training back in their schools. One teacher commented that the imperative to disseminate the work back in school empowered them to share their learning with all of the staff, and they could 'see the value of this and recognise that it was right for the children, their families and the whole school'. Alongside the cascading of training by the attendees of the AAS programme, schools also commissioned external trainers to provide bespoke attachment aware training in their schools.

It was the imperative to apply the developing theoretical understanding within their own settings that provided the impetus to consolidate the learning of the AAS participants. The participants were supported to conduct action research, and through this they were challenged to look at situations in different ways and encouraged to deepen and develop their school's 
practice around vulnerable learners, their families and carers. The guidance and support they received through the programme helped them to refine their ideas and to create a shared vision for their school. As the action-research work progressed and deepened in each of the settings, schools reflected upon how staff had developed their understanding and their practice. One participant commented that, 'Staff are now not blaming themselves or taking behaviour in a personal way,' adding that, within such a holistic context, 'they are better able to use their logical brain rather than react emotionally themselves'. As a direct result of the AAS programme a greater number of staff noted that they felt more empowered and reported that they now deal with difficult situations more successfully. One participant noted: 'lots of positive affirmation of individual pupils now takes place on a daily basis and lunchtime staff are much further on in their understanding of pupils.'

The need to support sustainable change was present from the start of the programme, in part through placing an emphasis upon identifying key staff to continue to champion attachment awareness in each setting. Participants in one secondary school reported that new members of staff are now provided with training in attachment theory as part of their induction and they also ensure that it is something which is embedded in the recruitment process. In another school, PGCE students now spend time, as part of their training, in an inclusion learning facility, learning about the work the school have embarked on through the AAS programme including input about attachment theories.

The emphasis upon reflective practice, driven by the action-research element of the programme has shown significant benefits for school staff. Staff reflect that they can only ever control their own behaviour and that they want students to reflect upon themselves. Moreover, they have noted that, 'teachers and staff can't change behaviour', but more importantly they are now able to support students to adapt and develop their own behaviour. 
Teachers have reported that they have developed new strategies for vulnerable learners at risk of not engaging or flourishing in their learning which has had a positive impact on the whole school. This recognition of how a greater understanding of attachment needs and related practices might support each and every adult-child encounter reinforces the growing belief and realisation that all the children who an adult works with are benefitting from staff's improved understanding and practice. Some staff already had an understanding of attachment before the programme began, but the programme has deepened and consolidated their knowledge further. The theoretical inputs, and action-research process allows the participants and staff in schools to understand to a greater degree why they do what they do and gives them the confidence to implement approaches which are grounded in theoretical understanding. Training and knowledge about attachment has informed staff and given them a new perspective on how they can manage and support behaviour. Many staff now have a better understanding of emotional regulation and the fact that some students are not yet ready to self-regulate, and need support to manage their emotions, with one participant commenting, 'Emotion coaching training has made people adapt their responses to lots of children's issues'.

\section{(4) Impact on Pupils}

Staff report that, through the AAS programme, they are supporting young people to manage their own behaviour to greater effect, so that young people can now self-regulate more often. Teachers have commented that investing in developing positive relationships with key adults gives children increased confidence. The participating schools have reported a wide range of improvements for their pupils. These include more positive relationships in school, better and happier school experiences, where children feel safer and more secure at school, lower anxiety levels, less stress and worry which in turn has led to improved self-esteem, and 
improved behaviour (with less disruption and fewer incidents) and consequently better learning. Schools report that specific children are able to self-regulate better when necessary, and they have demonstrated greater empathy and understanding for others. Schools have reported that through the AAS programme their whole school ethos has shifted where adults model an ethos of care and consideration resulting in children being more empathic to each other. One school noted that pupils involved specifically as part of the action-research programme have been described by staff as 'more rounded individuals; socially, emotionally, academically' and that this had a positive impact on all students. In some cases, direct input might have been specifically targeted towards small groups of young people, but often the positive impact has been seen and evidenced much further. Schools have identified that there can be a cascade effect from working with a key group of children which has had positive impacts on many other students around them.

Placing and holding the child at the centre of everything the school does demands greater dialogue with all members of the school community. Participants report that it involves 'going the extra mile for children, parents and carers' and also in working hard to gather background information about a child, and listening effectively to them to ensure that they really start to understand them and their presenting behaviour. Such knowledge and understanding has often emerged from placing an emphasis upon the importance of listening to a child's voice, avoiding making assumptions and looking at situations more deeply. Spending time with, and listening to, the children emerged as an overriding theme from many of the schools who identified that listening to the child's voice, for example through focus groups, has been key to their success (Bloor et al., 2001). This has included staff having to reflect on what children really want. At one school it was discovered that a group of children didn't want more free play, as was first thought, but instead they wanted to engage more with adults in their play. Such an approach not only conveys that adults are open and accessible 
but that children and young people can lead the learning in a school. One school (a specialist provision) had identified, through the work of the programme, that there was a need to directly work with pupils on their specific needs. That school now employs an Occupational Therapist for one day a week, to improve provision for those students with specific physical and sensory needs. Schools have identified the importance of helping children and young people to support each other through peer to peer support systems. They have also seen the power of providing a 'familiar face' for children starting school and investing in building relationships with someone before they even start there. They note that the AAS programme has 'helped to build resilience, a sense of community, and has relieved stress on staff'. Children themselves have been consulted in the schools (in one school they gave their opinions on the furnishing of a nurture area) and staff in one school specifically commented that children in their school now felt more safe and secure.

\section{(5) Extending relationships with parents/carers}

Some of the schools identified that to support their vulnerable children and young people to greater effect, they had to work much more closely with their parents. Many of these schools understood that developing a positive attachment to school had to begin from the perspectives at home, and that bridging the gap between school and home, through building more positive relationships with parents and carers was key. Schools noted that unstable home environments require that school is seen as a place of permanence for the young people, and also that establishing a strong link between school and home was also crucial; for example, through using transitional objects and shared language. Some schools highlighted the importance of increasing parental engagement in order to improve resilience, build greater self-esteem, and create more opportunities for self-regulation and co-regulation, for parents, carers and the young people themselves. Often this meant tackling and breaking a cycle of 
negativity, by building greater trust. For example, in one primary school their focus was placed upon the development of a personalised mentoring project for the children, their parents and carers. Through this they identified that a more consistent, open and honest line of communication was essential, and this has been established and maintained between school and home. This resulted in the development of strong and trusting relationships between school, the families and their children and working very closely with external agencies involved in the lives of the children. Parental engagement across this particular school increased and the role of Pastoral Manager has now been made into a permanent position. As a result of such a specific focus one senior teacher at the school noted that parents of this particular school now see the school as 'a family' which has helped to promote more positive relationships.

Developing such strategies and seeing investment in school-based staff, who become the brokers and facilitators between the many adults and services around the child, demands a very particular resource commitment, but many of the AAS schools feel that such roles are not only desirable, but they are essential. One carer of a child at one school reflected: 'I've been a carer for sixteen years and you're the first school who has understood attachment, let alone mentioned it as an issue itself!' Many of the AAS schools reflect upon the fact that being an AAS School reassures parents and carers (particularly adoptive parents) that the school will be an accommodating and positive place for the children in their care.

Of course, through the programme, participants did also encounter challenges and difficulties, and these were 'held' and 'contained' with reference to the process of action research. Through this, problems are seen as part of the process and that a community of action researchers can give support to participants, particularly where they had encountered similar issues in their school. Common issues included 'how to build an alliance of staff 
interested in working in this way', 'how to gauge the right time to provide training for staff in school' and 'whether to provide in-house training in school or to bring in an external provider'. These dilemmas, and others, were held by the group and with facilitation of the programme leads, reflective practice approaches were used to help provide support.

\section{Limitations}

This article outlines the evaluation of the first year of the AAS programme and therefore does not capture the subsequent data which, although anecdotally seems similar, through rigorous analysis may yield additional or different results. Therefore, further analysis of the next years of the AAS programme would be advantageous. For schools, alongside this yearlong school development programme, they will have also been developing their systems and organization in other ways. This means that it is possible that some of the effects cited in this work may have been partially, attributable to other factors and it has not been possible to mitigate against that risk other than to ask the participants in the interviews about what they believe the impact of the AAS programme has been. Also, measurement of the changes in schools of the type outlined in this work are inherently difficult to measure in a standardized manner and consequently this may affect the results in ways which are currently unknown. The research methods for this programme were selected at the outset and therefore without the benefit of hindsight. They have proven to be useful tools and means to evidence the evaluation. It may have been beneficial to add questions or measures to help schools to identify how much the impact they saw was due to the AAS programme, as opposed to other school development, and also to explore any 'cross-fertilisation' of these factors. These limitations could be considered for any future evaluations of the programme.

\section{Conclusion}


The AAS programme has had a fundamental impact upon the ethos of all of the schools involved. Schools report that the programme has become an integral part of what they do on a daily basis. It has provided them with the knowledge and understanding of the importance of an attachment aware approach which has shaped their whole school ethos, pedagogy and practice. The work has impacted upon both the content of conversations and the language used. Schools report that developmental trauma and attachment needs are now routinely discussed alongside academic needs, which has changed language used in school by all staff describing behaviour and has led to improvements in the ways the schools support young people with challenging behaviour.

Attachment awareness has been placed firmly on the map in Derbyshire and is continuing to challenge practices and policies. AAS schools report that they have become more inclusive, and that they see staff conversations have really changed around behaviour, to include seeing the context of the whole child. Many participating schools have moved away from a behaviourist approach of rewards and sanctions towards a supportive and inclusive ethos. The programme has facilitated systemic changes, and led to the creation of many more safe spaces and nurture areas in schools which are integrated meaningfully into the whole school structure. AAS schools report that this has led to 'happier children' who feel more valued and listened to within more nurturing and caring environments. As one school commented: 'the caring community radiates from the caretaker to the headteacher.'

An emphasis upon reflective practice has enriched and empowered staff and this has led to a significant and positive impact. Across the settings there has been a more holistic approach to working with children and young people and a higher importance has been placed on their emotional needs being met, demonstrating a re-positioning of an emphasis upon wellbeing 
and supporting a sense of belonging. Of course, this has demanded a continuity of process, even when the yearlong programme ended this is certainly not the end of the programme for the schools. Some headteachers commented that even though a small number of staff were resistant at first, the continuing training had played a crucial role in pulling the staff team together and shifting the school ethos. Many of the schools noted that it takes time to see the changes but that the programme has a 'real and lasting effect.' The paradigms of action research and reflective practice have been instrumental in that sense of 'ownership' and 'longevity'; rather than a training programme to be delivered to schools, the AAS programme has been a journey of development with schools. Indeed, it is evident that although the schools did implement some 'attachment aware strategies' in their schools, it was the process of developing better understanding in their schools which has led to a more empathic, personcentered approach where the depth of learning has gone far beyond the implementation of any particular strategy. Participants reported having benefitted far more from such an active development programme including action research and reflective practice than from a passive 'training delivery' model.

Several of the AAS schools have attributed recent positive Ofsted inspection comments to the work they have engaged in through the AAS programme. The inspectors have commented on the outstanding care and support provided for vulnerable children and families, the positive ethos of the schools, the focus on emotional well being and the impact of these on outcomes in learning.

Recognition of this work by the schools themselves, the wider community and other professional bodies has been testament to the dedication of the adults and young people within those schools working together in a paradigm built on attachment principles, with a focus on relationship-building through empathic and attuned interactions. 


\section{Acknowledgements}

This work was funded by The Virtual School, Derbyshire County Council.

\section{References}

Ainsworth, M. (1969). Attachment and exploratory behavior of one year olds in a strange situation. In B.A.Foss (Ed), Determinants of infant behavior, 4. London: Methuen Bazalgette, L., Rahilly, T., and Trevelyan, G. (2015) Achieving emotional wellbeing for looked after children: a whole system approach. What works in promoting good emotional wellbeing and mental health for children in care. NSPCC

Bergin, C. and Bergin, D. (2009) Attachment in the Classroom. Educational Psychology Review, 21, 141-170

Bloor, M., Frankland, J., Thomas, M., and Robson, K. (2001) Focus Groups in Social Research. London: Sage Publications.

Bowlby, J. (1969) Attachment and loss. Vol. 1: Attachment (2 ${ }^{\text {nd }}$ Ed.). New York: Basic Books

Bowlby, J. (1988) Attachment, Communication and the Therapeutic Process. A Secure Base: Parent-Child Attachment and Healthy Human Development, 137-157

Bowlby, R. (2007) Babies and toddlers in non-parental daycare can avoid stress and anxiety if they develop a lasting secondary attachment bond with one carer who is consistently accessible to them, Attachment \& Human Development, 9:4, 307-319

Braun, V. and Clarke, V. (2006) Using Thematic Analysis in Psychology. Qualitative Research in Psychology, 3 (2).pg. 77-101

British Psychological Society (2006). Code of Ethics and Conduct. Leicester: BPS 
British Psychological Society (2018). Code of Ethics and Conduct. Leicester: BPS

Cairns, K. (2004) Attachment, Trauma and Resilience: Therapeutic Caring for Children. London: British Association for Adoption and Fostering

Cozolino, L (2014). The Neuroscience of Human Relationships: Attachment and the Developing Social Brain. New York: W. W. Norton \& Company

Geddes, H. (2006). Attachment in the classroom. The links between children's early emotional wellbeing and performance in school. London: Worth

Kelly, G.A. (1963). A Theory of Personality: The Personality of personal constructs. New York: Norton

Kelly, P. (2011). Teachers' and Educational Psychologists' Constructs of Attachment (Unpublished doctoral thesis). University of Manchester

Legislation.gov.uk. (2014). Children and Families Act 2014. [online] Available at: http://www.legislation.gov.uk/ukpga/2014/6/contents/enacted [Accessed 11 Jan. 2015].

National Institute for Health and Care Excellence (2015) Children's attachment: attachment in children and young people who are adopted from care, in care or at high risk of going into care. NICE guideline (NG26)

Parker, R., Rose, J. and Gilbert, L. (2016) Attachment Aware Schools - an alternative to the behaviourist paradigm. In Noddings, N. and Lees, H. The International Handbook of Alternative Education. London: Palgrave

J. Rose, R. McGuire-Snieckus, L. Gilbert \& K. McInnes (2019) Attachment Aware Schools: the impact of a targeted and collaborative intervention, Pastoral Care in Education, 37:2, 162-184 
Schore, A.N. (2001) The Effects of Early Relational Trauma on Right Brain Development, Affect Regulation and Infant Mental Health. Infant Mental Health Journal 22(1-2) 201269

Schore, A. N. (2002). Advances in neuropsychoanalysis, attachment theory, and trauma research: Implications for self psychology. Psychoanalytic Inquiry, 22(3), 433-484

Sebba, J., Luke, N. \& Berridge, D. (2018) The educational progress of young people in out-of-home care. Developing Practice, 47

Stevenson, C. \& Copper, N. (1997) Qualitative and Quantitative Research. The Psychologist. 4. 159-160

Trevarthen, C. (2011). What young children give to their learning, making education work to sustain a community and its culture. European Early Childhood Education Research Journal, 19, 173-193

Willig, C. (2001) Introducing Qualitative Research in Psychology. Open University Press. Philadelphia 